\title{
Reading Books and Reading Minds: Differential Effects of Wonder and The Crossover on Empathy and Theory of Mind
}

\author{
MARTHA S. GUARISCO \\ THE EPISCOPAL SCHOOL OF BATON ROUGE
}

CELINE BROOKS

WEST VIRGINIA UNIVERSITY

\section{LOUISE M. FREEMAN}

MARY BALDWIN UNIVERSITY

We tested sixth graders for empathy and theory of mind before and after an academic unit on either Wonder or The Crossover. Wonder was associated with improved perspective-taking; students who read The Crossover increased in concern for others. Faux pas detection increased in both genders with Wonder, and in girls with The Crossover. Students who read The Crossover in print showed improved understanding of facial expressions, while students who used iPads declined. Young adult fiction is associated with improved social cognitive skills, but effects depend on gender and reading format, as well as on the choice of individual book.

Recent psychology research (Djikic \& Oatley, 2014, review) has documented social as well as academic benefits from reading fiction. Adult fiction readers are more sociable, more open to experience, more empathic, and better attuned to the feelings and thoughts of others (Kidd \& Castano, 2013; Mar et al., 2006; Mar, Oatley \& Peterson, 2008; Stansfield \& Bunce, 2013). Experiments in adults have shown that reading fiction can have immediate measurable effects: increasing altruism, tolerance, perspective-taking, and theory of mind skills (Bal \& Veltkamp, 2013; 
Djikic, Oatley \& Moldoveanu, 2013; Kidd \& Castano, 2013; Johnson, 2012; Johnson, Cushman, Borden \& McCune, 2013a; Johnson, Jasper, Griffin, \& Huffman, 2013b). Theory of mind is defined as the ability to "read" the thoughts and emotions of another; it includes such skills as interpreting facial expressions or body language, recognizing another's false belief, and determining whether an action is deliberate or accidental.

Engaging adolescents with fiction during an important developmental period would presumably have similar benefits. However, few studies have investigated whether young adult literature has prosocial effects on its intended age group. Kidd and Castano (2013) found that only literary, not popular fiction, improved theory of mind in adults; whether that distinction is meaningful for younger readers is unknown. As the young adult fiction market grows, students' reading habits change with technology, and teachers try to choose the most beneficial books for classroom use, understanding the psychological effects of different reading experiences on young readers is crucial.

We previously reported (Guarisco \& Freeman, 2015) that sixth graders' perspective-taking skills increased after a 5-week reading unit on Wonder (Palacio, 2012). Here, we report three major and novel results, expanding our original experiment.

- We replicated the empathy increase after reading Wonder and extended them to a second book, The Crossover (Alexander, 2014). However, the two books differed in the specific subtype of empathy that improved after reading.

- We found that both books were associated with improved theory of mind skills, although some effects were restricted to girls.

- We found preliminary evidence that some of the prosocial effects of reading were eliminated when students read the book in electronic format rather than traditional print. Furthermore, boys reported more engagement with reading when using iPad readers and girls more engagement with traditional books.

\section{THE CHOICE OF BOOKS}

The Crossover, the 2015 Newbery Medal winner, is a middle grade novel told in verse about twins Josh and Jordan "J. B.” Bell, both seventh grade basketball players. Josh struggles with loneliness and jealousy as his brother develops a romance with a new girl, Alexis. In a bet gone wrong, J. B. cuts off several of Josh's dreadlocks, a significant part of Josh's identity. Meanwhile, their father, a 
former basketball star, develops heart trouble. Josh's fear, anger, and frustration mount, and during a game, he throws a basketball at J. B.'s face. While the violent outburst does not break J. B.'s nose, it does break their relationship. Their father suffers two major heart attacks, the second one fatal. As the twins mourn, they restore their relationship.

Wonder features multiple narrators in the story of 10-year-old Auggie, born with severe facial deformities and attending school for the first time. A classmate, Jack, befriends him, but when Auggie overhears Jack disparaging him to other students, their relationship is broken. They repair their friendship only after Jack punches Julian, a student who has been bullying Auggie and subsequently targets Jack. In the end, Auggie's previously wary classmates stand up for him, and he gains the acceptance he has been seeking.

Both novels have much to offer for classroom use. Along with the Newbery Medal, The Crossover received the Coretta Scott King Author Award, the NCTE Charlotte Huck Honor, the Lee Bennett Hopkins Poetry Award, and the Passaic Poetry Prize. Its accessible themes and energetic language bring poetry alive. Wonder, a New York Times bestseller, won the 2014 Maine Student Book Award, Dorothy Canfield Fisher Children's Book Award, the 2015 Mark Twain Award, and the 2015 Nene Award. Its emphasis on kindness inspires rich discussion about inclusiveness. Along with its potential to enhance student empathy (Guarisco \& Freeman, 2015), Wonder has been used to help preservice teachers understand children with disabilities (Hayn, Clemmons \& Olvey, 2016).

We offered students a choice between novels for several reasons. Foremost, we wished to expose students to more young adult fiction of value. With limited time and an abundance of quality middle grade literature, the choice allowed inclusion of two noteworthy texts, rather than just one. Many students had read Wonder previously; we hoped offering a choice would increase reader engagement. Finally, teacher enthusiasm was essential; the books are two of her favorites. To help students make an informed choice, the teacher read the first poem from The Crossover aloud and gave book talks on both novels.

\section{FICTION, EMPATHY, AND THEORY OF MIND}

During early adolescence, children must cope with an increasingly complex social structure. Some empathic tendencies (concern for others, adopting another's viewpoint) increase in girls, but decrease in boys, amplifying already existing gender differences (Van der Graaf et al., 2014). 
Emotional projection into fiction also increases in both genders (Hawk et al., 2013). While this increase is associated with higher willingness to help others, agreeableness, and openness, this fondness for fantasy is also associated with social anxiety and emotional instability in teens (Hawk et al., 2013).

Both empathy and theory of mind skills are enhanced by stimulating social environments, even at young ages. Exposure to storybooks is associated with better theory of mind skills in preschoolers (Mar, Tackett, \& Moore, 2010). Social cognitive skills mature throughout adolescence and remain malleable to environmental factors. For example, a year of acting classes at age 14 increased both empathy and theory of mind skills; comparable lessons in music or art did not (Goldstein \& Winner, 2012).

If literary fiction improves understanding and compassion, exposure could be especially crucial during middle school. The social benefits of fiction reading in adults are not duplicated with nonfiction (Mar et al., 2006; 2008; Kidd \& Castano, 2013). Given the fears of some educators (e.g. Baurline \& Stotsky, 2012) that Common Core mandates could reduce the amount of fiction taught in secondary schools, more research is needed on the psychological effects of multiple reading genres on students. At the same time, more students are using electronic reading devices rather than traditional print books (Barnyak \& McNelly, 2015; Goodwyn, 2014). Recent studies (Mangen \& Kuiken, 2014; Mangen, 2016) suggest that emotional transport into stories may be reduced in digital media. Given this classroom trend, it is important to know if fiction's psychological impact changes with technology.

The potential of fiction for character development. Personality traits, including empathy, are typically resistant to long-term change. Personality psychologist McCrae and colleagues quip, "Had Dickens been striving for verisimilitude, he would have ended his fable on Christmas day; a year later, a real Ebenezer Scrooge would likely have reverted to his prototypically disagreeable self” (McCrae, Gaines \& Wellington, 2012, p. 71). Even if mental transport into fiction produces short-term increases in social cognition, how do such changes persist in the long term?

Djikic and Oatley (2014) have proposed that simulated social contact within fiction induces temporary, individualized fluctuations in personality that facilitate more long-term change. They cite two types of research studies in support of their model. The first are controlled laboratory experiments (e.g. Kidd \& Castano, 2013; Johnson 2012) that demonstrate immediate effects of 
reading fiction on empathy, compassion, or theory of mind. The second are correlational studies (e.g. Mar et al, 2006; 2008) that show associations between social cognitive skills and long-term reading habits. Unfortunately, experimental evidence for effects that fall between the two is lacking.

Missing, currently, from studies of this type are experiments on longer-term effects. For instance, people may be randomly assigned to read for, say, 10 hours a week over a period of several months, either fiction or nonfiction of their choice. (Djikic \& Oatley, 2014, p. 499)

Studies of school-based academic units, where students focus on careful reading and in-depth book study for several weeks, provide natural opportunities for the type of intermediate-term studies needed to close this research gap. To date, few researchers have explicitly addressed how students' social attitudes change after studying a piece of fiction. Published experiments have focused on reducing specific prejudices rather than increasing general empathy. While several teams (e.g. Cameron \& Rutland, 2006; Cameron, Rutland, Brown \& Douch, 2006; Vezzali, Stathi \& Giovannini, 2012; Vezzali et al., 2014) have reported increased tolerance after multi-week behavioral interventions involving reading and discussing stories about stigmatized groups, it is not clear to what extent such interventions contribute to the schools' academic goals.

Insights from the previous Wonder study. In our earlier study (Guarisco \& Freeman, 2015), we measured general empathy rather than attitudes towards a stigmatized group. We tested students before and after an academic unit that was part of the planned English curriculum. Although classroom activities, including an empathy exercise led by the school guidance counselor, emphasized Wonder's "Choose Kind" theme, students also studied the book for traditional English curriculum learning goals: to build reading comprehension and analytic skills, and to understand literary concepts like allusion, idioms, setting, characterization, and perspective.

After the Wonder unit, we observed a small but significant increase in one empathy subscale: Perspective Taking. The benefits of experiencing the character Auggie's challenges, from both his own and others' perspectives, generalized beyond compassion for those with physical disfigurements. After the unit, students reported more inclination to examine situations from another's point of view, an important social skill for reducing conflict and improving understanding. 
This research raised further questions. Could other middle grade books provide similar benefits? Had theory of mind improved along with empathy skills? Was the increase in Perspective Taking a result of Wonder's multiple narrators, suggesting a link between literary and psychological perspectives?

\section{THE CURRENT STUDY}

Our goal was to test the effects of a similar reading unit on three empathy measures, along with two theory of mind skills. Students were able to choose between reading Wonder or The Crossover. Additionally, two classes were assigned to read traditional print books, two were assigned to read a digital copy on iPads, and the fifth had a choice of reading format. By expanding the students' choices of texts, the number of variables measured and the options for reading format, we hoped to better understand young adult fiction's effects on social cognition.

\section{METHOD}

\section{Participants}

Participants were Martha Guarisco’s 89 sixth-grade students (48 M, 41 F) from the Episcopal School of Baton Rouge, Louisiana, divided into five class sections of approximately 18. Parents gave informed consent for student participation, while the students gave written assent. The school principal gave permission for the study and the Institutional Review Board of Mary Baldwin University approved all psychological testing procedures.

\section{Procedure}

Baseline assessment. The 5-week academic unit began in September 2015. Surveys were administered on school iPads, using the Qualtrics survey system, after books were selected, but before reading began. Students completed a demographics questionnaire listing their gender, race, book choice, whether they had read either novel previously, and whether they planned to use digital or paper copies. To assure anonymity, while also allowing comparison of individual scores before and after the unit, students identified their tests with school passwords.

Next, students completed three psychological assessments:

The Interpersonal Reactivity Index (IRI). The IRI is an established measure of empathy (Davis, 1981). We used three IRI subscales: Empathic Concern (feelings of sympathy and concern for others); Perspective Taking (the tendency to adopt another's point of view); and 
Fantasy Scale (the tendency to transport mentally into fictional works). Students read 21 statements (seven per subscale) and rated themselves for each on a 5 -point Likert scale $(1=$ not at all like me, $5=$ very much like me). Maximum score for each subscale was 35. Sample items included:

- I am often quite touched by things I see happen (Empathic Concern).

- I sometimes try to understand my friends better by imagining how things look from their perspective (Perspective Taking).

- I really get involved with the feelings of the characters in a novel (Fantasy Scale).

Reading the Mind in the Eyes Test for Children (Eyes-C). This is a wellvalidated theory of mind test for children that measures the ability to infer emotional state from a picture of the eyes (Baron-Cohen et al., 2001). Scores on the adult version of this test show improvement after reading literary fiction (Kidd \& Castano, 2013). There were 28 questions, each with a black-and-white rectangular photo of a pair of adult eyes. Children were asked, "What do you think this person is feeling?" and chose one of four descriptive terms. Each question was presented on a separate computer screen. Maximum score was 28.

The Faux Pas Test for Children (FP-C). This theory of mind test requires recognizing faux pas: social errors caused by false belief (Baron-Cohen et al., 1999). We used five stories in depicting a faux pas and five control stories with no such gaffes (Table 1). To receive credit, the child had to 1) recognize whether a faux pas had occurred 2) identify the faux pas if present 3) demonstrate story comprehension by answering a multiple-choice content question and 4) recognize the triggering false belief. Students read each story on one screen; questions were presented on subsequent separate screens. Maximum score was 5 on both the faux pas and control sections.

\section{Academic Unit Activities}

Instructional landscape. All students were taught by the same teacher, completing most reading in class with occasional homework reading. General mini-lessons on characterization and literary features, close readings, and empathy were presented as whole-class instruction, while content specific to the books was done in small groups.

Characterization and literary perspective. Before reading, students were placed into groups of four and assigned a particular character to observe closely over the course of the novel. As they read, groups considered characterization, noting physical descriptions, character 
actions, character speech, and reactions of other characters on a chart.

To encourage them to consider events from multiple perspectives, students were guided through a close reading exercise. For Wonder, students examined a scene, presented from both Auggie's and Via's perspective, in which Auggie cuts a braid that he has been growing for years. For The Crossover, students focused on Josh's violent act toward J. B, narrated from Josh's perspective. In groups, students completed a chart asking: What plot events happen in this scene? How is each character feeling? What is the cause of the events? For Wonder, students considered the event from Auggie's, Via's, and their mother's perspectives. For The Crossover, students evaluated the perspective of Josh, J.B., and their father. They highlighted things that all three characters would agree upon and concluded that the characters would view only the plot events with consensus.

Empathy exercise. Midway through the unit, the middle school guidance counselor facilitated a lesson about emotions, empathy, and healthy coping. She showed a video, Under the Surface (Wideman, 2014), about high school students facing problems invisible to others. After discussion, she asked students to list emotions they might experience on a given day and presented different names for those emotions. Students brainstormed healthy and unhealthy ways of coping.

Fostering engagement. Throughout the novel unit, students had opportunities to make personal connections to the text. Before reading, students did two 5-minute, informal writing pieces to get them thinking about their novel's theme. The Wonder readers responded to prompts asking them to consider what the word "normal" might mean, while the Crossover readers wrote about ways relationships can be both helpful and harmful. Students also responded to discussion questions (Table 2) in small groups.

Both texts feature an adult offering wisdom to the adolescent characters. In Wonder, Mr. Browne gives his students monthly "precepts," or words to live by, asking them to respond in writing. In The Crossover, Chuck Bell gives his sons rules which apply both to basketball and to life. At the end of the novel, students wrote formal essays explaining how one of the precepts or rules illustrates the book's theme.

Literary analysis. Students also focused on literary aspects of the novels, with minilessons on allusions, conflict, and setting. In addition to their precept/rule essay, students worked in groups to create a "character-in-a-bag," that included an illustration, evidence to support whether their character was static or dynamic, three important quotations, and descriptions of conflicts the 
character faced. Inside the bag, they included ten objects that represented the character.

Final psychological assessment. Approximately one week after reading was finished and shortly after the character-in-a-bag projects, students took the IRI, Eyes-C, and FP-C tests again. The IRI and Eyes-C tests were identical to the first session; the FP-C was identical in format but included five different faux pas and control stories. We hypothesized that empathy and theory of mind scores would increase from the first to the second test session.

\section{RESULTS AND DISCUSSION}

\section{Sample Demographics}

Eleven children failed to complete both surveys or provided non-matching codes, leaving 78 participants (41 M, 37 F) with usable data. The majority of students (63/78) identified as Caucasian. Other racial groups represented were African-American (8), Asian (4), Latino (1), Native American (1) and Other (1). Because of the low number of minority participants, we did not quantify effects of race.

More students (57/78) selected The Crossover than Wonder. There was no relationship between gender and book choice. In the initial questionnaire, only 20 of the 78 students reported that they planned to read the book on the iPad. However, last-minute changes resulted in additional students being assigned to digital reading. In the single class section where students were allowed to choose reading format, 4 of 18 picked the digital book. At the final assessment, 33 students reported reading digital and 45 print. Thirty-two students $(18 \mathrm{M}, 14 \mathrm{~F})$ had read Wonder previously; the majority of those students (25) choose The Crossover for the unit. One boy had previously read The Crossover; no one had read both books.

\section{Baseline Differences}

The first step in data analysis was to identify any group differences present before reading began. Researchers have found consistent gender differences in IRI scores by age 13 (Hawk et al, 2014; Van der Graaf et al., 2013), although we did not see such differences in our previous Wonder study (Guarisco \& Freeman, 2015). Gender differences in Eyes-C scores (Baron-Cohen et al., 1999) have been reported in early adolescence. Since students chose their own books, we also had to consider selection effects; it is possible that initial reader empathy levels could affect the appeal 
of a book. Baseline effects of gender, book choice, and anticipated reading format on each assessment were evaluated by three-way between-subjects analysis of variance.

\section{Baseline gender differences in Empathic Concern and Perspective Taking.}

As expected, girls scored higher than boys on baseline Empathic Concern and Perspective Taking (Fig. 1a); no other baseline score showed gender differences. The effects of gender on these two measures also partially depended on book choice. Wonder readers had a significantly larger gender difference in Empathic Concern than The Crossover readers. Perspective Taking showed a similar pattern, with the difference between books bordering on statistical significance (Fig. 1b). This is evidence that Wonder attracted the more empathic girls, but the less empathic boys. The reason for the larger gender difference is unclear, but could relate to either story content or to Wonder being prose rather than poetry. The pattern of larger gender differences in empathy in Wonder readers persisted throughout the study, independent of other changes with reading.

Effect of gender and reading format on Fantasy Scale. Baseline Fantasy Scale scores were similar for both book groups, but depended on both gender and the format that the students anticipated reading. Among students who planned to read iPads, boys had higher Fantasy Scale scores than girls, indicating that they saw themselves more mentally connected to fiction. The gender difference was reversed in students reading print (Fig. 1c). The prospect of using the iPad might have increased the boys' enthusiasm about reading, so that they anticipated better engagement. Girls may have been less interested in the iPad, or more attached to the visual and tactile experience of traditional books.

At least in the Crossover group', this interaction of gender and reading format persisted throughout the study when we considered the format the students actually used. Fantasy Scale scores did not change significantly post-unit, but girls continued to have higher scores with traditional print, while boys had higher scores with iPads.

E-readers are still relatively new in schools, and research comparing reading outcomes with paper has yielded inconsistent results. Most studies report high student interest in e-books (e.g. Barnyak \& McNelly, 2015; Goodwyn, 2014; Huang, Liang \& Chui, 2013), but it is unclear whether this enthusiasm translates into more careful reading or better understanding. A small study (Wright, Fugate \& Caputa, 2013) of three second grade girls found similar reading comprehension

\footnotetext{
${ }^{1}$ The Wonder group was too small to expect to be able to detect an interaction effect of gender and reading format; only four boys and four girls read Wonder on the iPad.
} 
for iPad and traditional storybooks, with iPads increasing the likelihood of the child consulting dictionaries or other resource materials. Barnyak and McNelly (2015) found that early elementary students independently using e-readers for nonfiction texts recalled details better than those using print; however, neither group performed as well as a group reading the print books with teacher support. A study of Chinese sixth graders reading science texts on electronic tablets found that girls recalled the material better and were more likely to use note-taking applications than boys; boys were more likely to be distracted by drawing and game tools (Huang et al., 2013). Finally, effects of technology also depend on age and familiarity with devices. Chinese college students recalled nonfiction better after reading it on paper than on a computer screen, with electronic tablets intermediate between the two; however, recall was higher in more experienced tablet users (Chen et al., 2014). Margolin, Driscoll, Toland and Kegler (2013) found no difference between computer, e-reader, or print reading comprehension in U.S. college students who routinely used educational technology.

Since mental transport into fiction is necessary for social benefits (Bal \& Veltkamp, 2013; Johnson 2012; Johnson et al., 2013a), our Fantasy Scale results suggest that effects of fiction could depend on what reading format students use, or anticipate using. Because our psychological assessments were collected anonymously, it was not possible to connect individual students' reported Fantasy Scale scores to academic outcome. However, post-hoc analysis of class grades found that, while reading format made no difference in scores on the unit test, scores on Renaissance Learning's STAR test (a gauge of reading level) showed a pattern similar to baseline Fantasy Scale: boys using iPads had the highest average score and girls using iPads the lowest. This raises the intriguing possibility that, in our students, the iPads benefited boys, improving both reading engagement and performance, while having the opposite effect in girls. An alternate explanation is that the stronger boy and weaker girl readers were placed, by chance, in the digital group, and that the stronger readers are also more caught up in fiction. Further experiments are needed on the impact of digital reading on both academic and social outcomes; such studies should consider possible gender differences.

\section{Changes in Empathy and Theory of Mind after the Reading Unit}

The second step of analysis was to determine whether empathy and theory of mind improved after the reading unit by comparing the students' post-unit scores to baseline. All the empathy subscales 
and theory of mind tests were assessed by four-way mixed-design analysis of variance. Because some of the effects of the academic unit depended on which book was chosen, data were analyzed separately for Wonder and The Crossover readers.

Our hypothesis that students would show improved empathy and theory of mind after the novel unit was confirmed. To our knowledge, this is the first study to show that middle grade novels are associated with both empathy and theory of mind improvements when read by their intended age groups. The improvement developed over a 5-week period of classroom study, and was present a week after reading ended, so it resembles the type of intermediate-term effect that Djikic and Oatley (2014) cite as missing from most studies of the prosocial effects of fiction. However, the two books had different effects, and both gender and book format modulated the effect of reading.

Wonder and The Crossover are associated with different empathy changes. Reading Wonder was associated with increased Perspective Taking (Fig. 2a), while The Crossover was associated with increased Empathic Concern (Fig. 2b). Neither gender nor reading format made a difference in the effect of The Crossover unit on Empathic Concern. However, effects of reading The Crossover on Perspective Taking marginally depended on gender. Boys' PerspectiveTaking scores were unchanged after completing the Crossover unit, while girls' trended downward slightly (Fig 2c).

Replication of previous Wonder study. The increase in Perspective Taking after reading Wonder replicates our previous study (Guarisco \& Freeman, 2015), even though the current sample was much smaller. Replication of findings is essential in all social sciences (Amir \& Sharon, 1990). In addition, this finding eliminates the possibility that the students in the previous study, who were atypical in lacking the expected gender differences in empathy (Guarisco \& Freeman, 2015) were also atypical in their response to Wonder.

Differences between Wonder and The Crossover. Engagement with fiction is thought to simulate social contact (Mar \& Oatley, 2008), improve the ability to understand others' thoughts and feelings (Kidd \& Castano, 2013; Johnson, 2012; Mar et al., 2008) and reduce prejudice (Johnson et al., 2013b; Vezzali et al., 2012). Therefore, Perspective Taking's failure to increase in the Crossover readers -and even slight decline (3.6\%) in girls (Fig 2c.)-may initially seem puzzling. However, there are several reasons that the two books might be associated with 
different changes in empathy.

One key difference is that Wonder's multiple narrators require considering the story from different viewpoints, while The Crossover is told only in Josh's voice. Direct experience with multiple literary perspectives may draw more attention to the benefits of adopting another's perspective in a real-life conflict. Second, readers may respond differently to Wonder's narrative prose than to The Crossover's verse. Recent functional MRI studies found that poetry and prose activated different brain regions, with poetry more likely to stimulate brain areas involved in emotional responses to music and introspection (Zeman, Milton, Smith \& Rylance, 2013). Prose may enhance empathy on a cognitive level, while verse acts on a more emotional mechanism. More research using a wider variety of texts is needed to determine if poetry affects social cognition differently from prose.

Finally, story content likely contributed to differing effects. Wonder ends on a happy note, with Auggie receiving an award for courage and feeling acceptance, not pity. While The Crossover ends with the brothers' reconciliation, the scene takes place during their father's funeral reception, where the family has been receiving condolences. Reading about the cultural expression of sympathy to the bereaved family may have triggered feelings of concern and sorrow for the twins that generalized into higher Empathic Concern scores.

Theory of mind effects vary with book and gender. An increase in faux pas question scores without a concurrent increase in control scores is evidence of improved theory of mind skills, rather than a nonspecific improvement in reading comprehension. Scores on the faux pas, but not control questions, increased significantly after the Wonder unit (Fig 3a). Changes after reading were the same in both genders and with both reading formats. For students who read The Crossover, the increase in faux pas scores was smaller (20.8\% compared to Wonder's 32.98\%) and restricted to girls (Fig 3b).

The increase in ability to detect faux pas may have been larger with Wonder because it includes several examples of social gaffes similar to the FP-C examples. One occurs shortly after Jack meets Auggie, when he asks, "Can’t you get plastic surgery or something?" Auggie, who has undergone 27 surgeries since birth, points to his face and responds, "Hello? This is after plastic surgery!” Later, Jack, under pressure from Julian, says he would kill himself if he looked like Auggie, unaware that Auggie is nearby, disguised in his Halloween costume. A third example is when Jack's wealthy classmate speaks of abandoning a broken sled in the park, joking that a 
"hobo" must have taken it. Jack, a scholarship student from a lower socioeconomic neighborhood, had found the sled, repaired it, and had been enjoying it as the finest he had ever owned.

Differences in Eyes-C scores with reading format. Changes in the second theory of mind test, the Eyes-C, were independent of changes in faux pas detection. No change in ability to infer emotions from eyes was seen in the Wonder group, perhaps because of smaller sample size. In the Crossover group, Eyes-C scores improved only in the students reading print; students using iPads actually declined on this measure (Fig 3c). This raises the intriguing possibility that reading format could affect fiction's ability to enhance some aspects of theory of mind. Unlike with Fantasy Scale, the effect of format on Eyes-C score was the same in both genders. Thus, even though boys felt more mentally engaged when using iPads, they declined in sensitivity to facial expressions.

Reading literary, but not popular, fiction is associated with increases in the ability to infer emotions from pictures of eyes in adults (Kidd \& Castano, 2013). Johnson (2012) found that reading and mentally engaging with a short story increased college students' sensitivity to fearful facial expressions, along with empathy and altruism. However, both of those experiments examined immediate effects; in our study, testing was a week after the students finished reading the novel.

To our knowledge, only one previous study has directly compared the emotional impact of reading in digital and print format. Mangen and Kuiken (2014) asked college students to read an emotional murder story from either paper or an iPad. Half of the participants were told they were reading fiction, and half nonfiction. For paper readers, transportation into the story was associated with higher empathy for the characters; this correlation was not seen in iPad readers. In addition, iPad readers reported less narrative coherence, reduced tendency to take the characters' perspectives, less sympathy for the characters and less sense of "losing" themselves in the narrative. However, these differences were present only in the group that believed they were reading nonfiction; reading format did not affect narrative engagement when readers believed the story was fiction.

Our finding that iPads and traditional books had opposite effects on the Eyes-C test scores is further evidence that the digital reading experience may differ psychologically from that of traditional print. Unlike in Mangen and Kuiken (2014), our e-readers improved in Empathic Concern to the same degree that print readers did, even as their sensitivity to facial expressions 
declined. However, we measured empathy for real-life acquaintances, not for the characters in the reading, and our students' assessments occurred a week after reading completion, rather than immediately. This "sleeper effect" is consistent with the research of Bal and Veltkamp (2013), who also found increases in empathy a week after reading.

Mangen and Kuiken (2014) also found that even experienced iPad readers were more likely to lose track of their place in the text and to report awkwardness when using the device. Both effects could have reduced connection to the narrative in our readers. The complex relationship between gender, technology, and reading requires more research by both literary specialists and behavioral scientists (Mangen, 2016). Our study underscores the need to consider emotional engagement and social effects, along with academic outcome, when evaluating the pros and cons of e-readers.

\section{GENERAL DISCUSSION}

\section{The Classroom Experience}

One disadvantage of classroom-based research is the difficulty of separating the effects of exposure to the specific text from those of other classroom activities. However, in the current study, students in the same class sections participated in similar learning activities while reading different books. Since changes in social cognition varied with book, they are likely to be in some way related to exposure to the specific text. If improvements were the result of other classroom experiences (e.g. the video exercise, small-group interactions, literary instruction), or developmental experiences beyond English class (e.g. becoming more familiar with schoolmates, adjusting to changes associated with middle school, or simple maturation), we would expect Wonder readers to increase in the same IRI subscale as the Crossover readers. Similarly, an increase in Eyes-C score with print and a decrease with iPad suggests changes are related to the reading experience; classroom activities would have been virtually identical for these two groups.

Classroom activities presumably encouraged extended and deeper reflection about the text, which may have helped psychosocial changes develop and persist (Bal \& Veltkamp, 2013). In Johnson's (2013a) short-term study of college students, guided imagery generation was necessary for a short story to have empathy-enhancing effects; no increase was seen in students instructed to read the story as they would for leisure. While we cannot rule out the possibility that the book groups differed because of different classroom sub-environment (e.g. book-specific writing 
prompts and discussion questions), it is clear that different books were associated with different social cognition outcomes. What is remarkable is that, with few exceptions, the changes were positive for both books.

Gender considerations. Our within-subjects design, which compares individual students' scores before the unit to those after, controls for expected gender differences and other baseline differences related to book selection or reading format. Boys had a larger increase (16.4\%) in Perspective Taking than girls (2.2\%) after reading Wonder; one explanation is that boys started lower (17.0, compared to the girls' 19.8) and therefore had more room for improvement. Other studies (Djikic et al, 2013; Johnson et al., 2013b) also have found that reading enhanced empathy only in those with lower starting points. The Crossover boys began with higher Perspective Taking than Wonder boys, which may have contributed to the lack of measurable improvement.

One exception to the positive psychosocial changes seen was the slight, marginally significant decline in Perspective Taking in girls who read The Crossover (Fig 2c). The reason for the decline is unclear, but could be related to the relative lack of female characters. The Crossover centers on Josh, J. B., and their father, whose relationship revolves around a typically male interest: basketball. Groups assigned to follow the twins' mother struggled to find relevant quotes and items to include in their character bag. No one was assigned to follow the other female character in The Crossover, J. B.'s girlfriend Alexis, since little is known about her until late in the book. Seen mostly through Josh's jealous eyes, she is usually referenced only as "Miss Sweet Tea.” In contrast, three of the six narrators of Wonder are girls: Auggie's sister Via, his friend Summer, and Via's best friend, Miranda. Girls may have better related to the well-developed and similarly-aged female characters of Wonder than to Josh's mother, who is also the assistant principal of his school and therefore a dual authority figure.

However, it is a disservice to label The Crossover as a "boy book." The slight decrease in girls' Perspective Taking was offset by gains in Empathic Concern that were comparable to the boys', and trends in improved faux pas detection that boys did not show (Fig. 3b). Although BaronCohen et al. (1999) reported that girls outscore boys on faux pas detection between the ages of 7 and 11, we saw no such gender difference at the beginning of our study. Only after reading The Crossover did girls surpass boys. The Crossover lacked the explicit social gaffe object lessons of Wonder, which was associated with improved faux pas detection in both genders. Simulated social contact may have been more subtle in the singly narrated poetry of The Crossover. Girls, with 
slightly higher beginning Empathic Concern and Perspective-Taking skills (Fig. 1b), may have been more sensitive to the social simulation, or more responsive to the academic activities. This could lead girls to more carefully consider interpersonal interactions where someone could be unintentionally hurt emotionally, and thereby glean more theory of mind skills from The Crossover. Boys may have focused more on the act of physical aggression that was a key plot point in that book.

Student Reactions. As we heed the call to include diverse books in the classroom, we note one interesting outcome from The Crossover. While completing their character-in-a-bag projects, several Caucasian students did not realize that the protagonists were African-American. Race is important, but often uncomfortable territory for classroom discussion. During group work, students re-read the section in which a police officer pulls over Josh's father, and Josh is clearly nervous that the situation could escalate. Most students did not realize the significance of this seemingly minor detail. The majority of the students who did not choose The Crossover for their novel study subsequently read it independently, in large part because the book generated so much positive buzz. Adding to their excitement was a planned visit from author Kwame Alexander in January.

Wonder also presented an opportunity to address broader social issues. Understanding the role of class conflict in Jack's character development required frank discussion of socioeconomic class and how it feels to be surrounded by students with lavish lifestyles. Surprisingly, students were eager to tackle this conversation, mentioning extravagant birthday parties and international travel. While the small group discussions on this topic were superficial, students were much more open to sharing in the whole class, with the teacher facilitating.

\section{CONCLUSIONS}

Efforts to introduce sixth graders to studying novels with Wonder and The Crossover were successful both on an academic and social level.

- Students showed increases in both empathy and theory of mind after the unit, suggesting that these two young adult books have social benefits similar to literary fiction for adults.

- Specific effects depended on the book, with Wonder associated with higher Perspective Taking and The Crossover with higher Empathic Concern.

- We also found evidence that theory of mind skills increased after the unit, although effects 
varied with book, gender, and reading format.

- The ability to detect faux pas increased in both genders after reading Wonder. For The Crossover, the increase was smaller and restricted to girls.

- No change was seen in ability to read emotions from faces in the Wonder group. For The Crossover, this ability increased in students who read the book in print, but decreased in students who used iPads.

- The observation that different empathy and theory of mind changes were associated with the two books makes it more likely that the changes were the result of exposure to the specific texts, rather than classroom activities, or other changes that happened within the school environment during the academic unit.

- All changes in empathy and theory of mind occurred over a 5 -week period and were present a week after reading was complete.

How long the improved social cognition skills persisted is unknown, but future studies could address that question by retesting later in the year, ideally after a period in which the students were not studying fiction.

\section{IMPLICATIONS FOR CLASSROOM TEACHERS}

There is more quality young adult fiction available than any teacher can possibly use in the classroom. Introducing diverse readings not only gives opportunities for children to engage with fiction that interests them, but also allows researchers to measure the capacity of individual books to increase compassion, understanding, and social cognition. Such studies, in turn, provide evidence to support teachers who wish to include these two books specifically, or young adult literature in general, in their curriculum. This evidence can be especially crucial for educators under pressure to reduce the time devoted to literature, replace fiction with the study of nonfiction, or use only "canon" texts.

Teachers interested in using young adult literature to increase student empathy can start by choosing texts that resonate with their readers. This requires a thorough knowledge of adolescent development, of issues they face, and of diverse texts. Empathy training is a natural fit for the literature classroom, as students consider how situations can be seen by different characters. In the words of John Green (2012), "Reading is always an act of empathy. It's always an imagining of what it's like to be someone else." 


\section{REFERENCES}

Alexander, K. (2014). The Crossover. New York: Houghton Mifflin Harcourt.

Amir, Y., \& Sharon, I. (1990). Replication research: A "must" for the scientific advancement of psychology. Journal of Social Behavior and Personality, 5(4), 51-69.

Bal, P. M., \& Veltkamp, M. (2013). How does fiction reading influence empathy? An experimental investigation on the role of emotional transportation. PloS one, 8(1), e55341.

Barnyak, N. C., \& McNelly, T. A. (2015). The literacy skills and motivation to read of children enrolled in Title I: A comparison of electronic and print nonfiction books. Early Childhood Education Journal, 1-10.

Baron-Cohen, S., O'Riordan, M., Stone, V., Jones, R., \& Plaisted, K. (1999). Recognition of faux pas by normally developing children and children with Asperger syndrome or highfunctioning autism. Journal of Autism and Developmental Disorders, 29(5), 407-418.

Baron-Cohen, S., Wheelwright, S., Spong, A., Scahill, V., \& Lawson, J. (2001). Are intuitive physics and intuitive psychology independent? A test with children with Asperger Syndrome. Journal of Developmental and Learning Disorders, 5(1), 47-78.

Bauerline, M., and Stotsky, S. (2012, Sep. 28). How Common Core's ELA standards undermine college readiness. Retrieved 10 June 2016 from http://pioneerinstitute.org/download/howcommon-cores-ela-standards-place-college-readiness-at-risk/

Cameron, L., \& Rutland, A. (2006). Extended contact through story reading in school: Reducing children's prejudice toward the disabled. Journal of Social Issues, 62(3), 469-488.

Cameron, L., Rutland, A., Brown, R., \& Douch, R. (2006). Changing children's intergroup attitudes toward refugees: Testing different models of extended contact. Child Development, $77(5), 1208-1219$.

Chen, G., Cheng, W., Chang, T. W., Zheng, X., \& Huang, R. (2014). A comparison of reading comprehension across paper, computer screens, and tablets: Does tablet familiarity matter? Journal of Computers in Education, 1(2-3), 213-225.

Davis, M. H. (1983). Measuring individual differences in empathy: Evidence for a multidimensional approach. Journal of Personality and Social Psychology, 44(1), 113.

Djikic, M., \& Oatley, K. (2014). The art in fiction: From indirect communication to changes of the self. Psychology of Aesthetics, Creativity, and the Arts, 8(4), 498-505. 
Djikic, M., Oatley, K., \& Moldoveanu, M. C. (2013). Reading other minds: Effects of literature on empathy. Scientific Study of Literature, 3(1), 28-47.

Goldstein, T. R., \& Winner, E. (2012). Enhancing empathy and theory of mind. Journal of Cognition and Development, 13(1), 19-37.

Goodwyn, A. (2014). Reading is now “cool”: a study of English teachers' perspectives on e-reading devices as a challenge and an opportunity. Educational Review, 66(3), 263-275.

Green, John. [CrashCourse]. (2012, November 12). How and why we read: Crash course English Literature \#1. [Video file]. Retrieved from https://www.youtube.com/watch? $\mathrm{v}=$ MSYw502dJNY.

Guarisco, M. \& Freeman, L. (2015).The wonder of empathy: Using Palacio’s novel to teach perspective taking. The ALAN Review, 56 (68), 56-68.

Hawk, S. T., Keijsers, L., Branje, S. J., Graaff, J. V. D., Wied, M. D., \& Meeus, W. (2013). Examining the Interpersonal Reactivity Index (IRI) among early and late adolescents and their mothers. Journal of Personality Assessment, 95(1), 96-106.

Hayn, J. A., Clemmons, K.R., \& Olvey, H.A. (2016) Fostering inclusion of disabled youth through young adult literature: Action research with Wonder. Study and Scrutiny: Research on Young Adult Literature 1(2): 64-78.

Huang, Y. M., Liang, T. H., \& Chiu, C. H. (2013). Gender differences in the reading of e-books: Investigating children's attitudes, reading behaviors and outcomes. Educational Technology \& Society, 16(4), 97-110.

Johnson, D. R. (2012). Transportation into a story increases empathy, prosocial behavior, and perceptual bias toward fearful expressions. Personality and Individual Differences, 52(2), $150-155$.

Johnson, D. R., Cushman, G. K., Borden, L. A., \& McCune, M. S. (2013a). Potentiating empathic growth: Generating imagery while reading fiction increases empathy and prosocial behavior. Psychology of Aesthetics, Creativity, and the Arts, 7(3), 306-312.

Johnson, D. R., Jasper, D. M., Griffin, S., \& Huffman, B. L. (2013b). Reading narrative fiction reduces Arab-Muslim prejudice and offers a safe haven from intergroup anxiety. Social Cognition, 31(5), 578-598.

Kidd, D. C., \& Castano, E. (2013). Reading literary fiction improves theory of mind. Science, 342(6156), 377-380. 
Mangen, A. (2016). The digitization of literary reading. Orbis Litterarum, 71(3), 240-262.

Mangen, A., \& Kuiken, D. (2014). Lost in an iPad: Narrative engagement on paper and tablet. Scientific Study of Literature, 4(2), 150-177.

Margolin, S. J., Driscoll, C., Toland, M. J., \& Kegler, J. L. (2013). E-readers, computer screens, or paper: Does reading comprehension change across media platforms? Applied Cognitive Psychology, 27(4), 512-519.

Mar, R. A., \& Oatley, K. (2008). The function of fiction is the abstraction and simulation of social experience. Perspectives on Psychological Science, 3(3), 173-192.

Mar, R. A., Oatley, K., Hirsch, J., de la Paz, J. and Peterson, J. B. (2006). Bookworms versus nerds: Exposure to fiction versus nonfiction, divergent associations with social ability and the simulation of social worlds. Journal of Research in Personality, 40, 694-712.

Mar, R. A., Oatley, K., \& Peterson, J. B. (2008). Exploring the link between reading fiction and empathy: Ruling out individual differences and examining outcomes. Communications, 34(4), 407-428.

Mar, R. A., Tackett, J. L., \& Moore, C. (2010). Exposure to media and theory of mind development in preschoolers. Cognitive Development, 25(1), 69-78.

McCrae, R. R., Gaines, J. E., \& Wellington, M. A. (2012). The five factor model in fact and fiction. Handbook of Psychology. 2nd ed. New Jersey: John Wiley \& Sons Inc.

Nomura, K., \& Akai, S. (2012). Empathy with fictional stories: Reconsideration of the Fantasy Scale of the Interpersonal Reactivity Index. Psychological Reports, 110(1), 304-314.

Palacio, R.J. (2012). Wonder. New York: Alfred A. Knopf.

Stansfield, J., \& Bunce, L. (2014). The relationship between empathy and reading fiction: Separate roles for cognitive and affective components. Journal of European Psychology Students, 5(3), 9-18.

Van der Graaff, J., Branje, S., De Wied, M., Hawk, S., Van Lier, P., \& Meeus, W. (2014).

Perspective taking and empathic concern in adolescence: Gender differences in developmental changes. Developmental Psychology, 50(3), 881.

Vezzali, L., Stathi, S., \& Giovannini, D. (2012). Indirect contact through book reading: Improving adolescents' attitudes and behavioral intentions toward immigrants. Psychology in the Schools, 49(2), 148-162.

Vezzali, L., Stathi, S., Giovannini, D., Capozza, D., \& Trifiletti, E. (2014). The greatest magic of 
Harry Potter: Reducing prejudice. Journal of Applied Social Psychology.

Wideman, A. (2014, February 11). Under the Surface. [Video file]. Retrieved from https://www.youtube.com/watch?v=AZ-pU7ozt3g.

Wright, S., Fugett, A., \& Caputa, F. (2013). Using e-readers and internet resources to support comprehension. Educational Technology \& Society, 16(1), 367-379.

Zeman, A., Milton, F., Smith, A., \& Rylance, R. (2013). By heart: An fMRI study of brain activation by poetry and prose. Journal of Consciousness Studies, 20(9-10), 132-158. 


\section{TABLE 1}

Sample Stories and Questions Used in the Faux Pas Test for Children (BaronCohen et al., 1999)

\begin{tabular}{|c|c|c|}
\hline & Faux Pas Question & Control Question \\
\hline Story & $\begin{array}{l}\text { Mike was in one of the cubicles in } \\
\text { the toilets at school. Joe and Peter } \\
\text { were at the sinks nearby. Joe said, } \\
\text { "You know that new boy in the } \\
\text { class, his name is Mike. Doesn’t he } \\
\text { look really weird?" Mike then } \\
\text { came out of the cubicles. Peter } \\
\text { said, "Oh, hello Mike, are you } \\
\text { going to play football now?" }\end{array}$ & $\begin{array}{l}\text { Michelle had just moved into a new } \\
\text { house. Michelle went shopping with } \\
\text { her mom and bought a new rug for her } \\
\text { bedroom. When Michelle had just put } \\
\text { it down, her best friend, Samantha, } \\
\text { came over and said, "Oh, your new } \\
\text { rug is just like my new one." Michelle } \\
\text { asked, "Do you like the house?" }\end{array}$ \\
\hline $\begin{array}{l}\text { Faux Pas } \\
\text { Recognition }\end{array}$ & $\begin{array}{l}\text { In the story, did someone say } \\
\text { something that they should not } \\
\text { have said? }\end{array}$ & $\begin{array}{l}\text { In the story, did someone say } \\
\text { something that they should not have } \\
\text { said? }\end{array}$ \\
\hline $\begin{array}{l}\text { Faux Pas } \\
\text { Identification }\end{array}$ & $\begin{array}{l}\text { What did they say that they should } \\
\text { not have said? }\end{array}$ & $\begin{array}{l}\text { N/A. Question not asked if first } \\
\text { question answered "no." }\end{array}$ \\
\hline $\begin{array}{l}\text { Story } \\
\text { Comprehension }\end{array}$ & $\begin{array}{l}\text { Where were Joe and Peter when } \\
\text { they were talking? }\end{array}$ & What had Michelle just bought? \\
\hline $\begin{array}{l}\text { False Belief } \\
\text { Identification }\end{array}$ & $\begin{array}{l}\text { Did Joe know that Mike was in the } \\
\text { cubicles? }\end{array}$ & Did Samantha know the rug was new? \\
\hline
\end{tabular}


TABLE 2

Discussion Questions Addressed by Students in Small Groups for Each Novel

\begin{tabular}{|l|l|}
\hline Wonder & The Crossover \\
\hline $\begin{array}{l}\text { Have you ever seen someone left out of a } \\
\text { group? How did that person respond? }\end{array}$ & $\begin{array}{l}\text { How can you tell if a middle school boy likes a } \\
\text { girl? }\end{array}$ \\
\hline $\begin{array}{l}\text { Why do you think friends sometime grow } \\
\text { apart? }\end{array}$ & $\begin{array}{l}\text { Have you ever taken a bet? What was it? Did } \\
\text { you win or lose? }\end{array}$ \\
\hline $\begin{array}{l}\text { Do you have a special relationship with any of } \\
\text { your relatives? What makes it special? }\end{array}$ & $\begin{array}{l}\text { Do your parents push you? Is that a good or a } \\
\text { bad thing? }\end{array}$ \\
\hline
\end{tabular}


FIGURE 1

Effects of Gender, Book Choice and Anticipated Reading Format on Baseline Empathy Scores

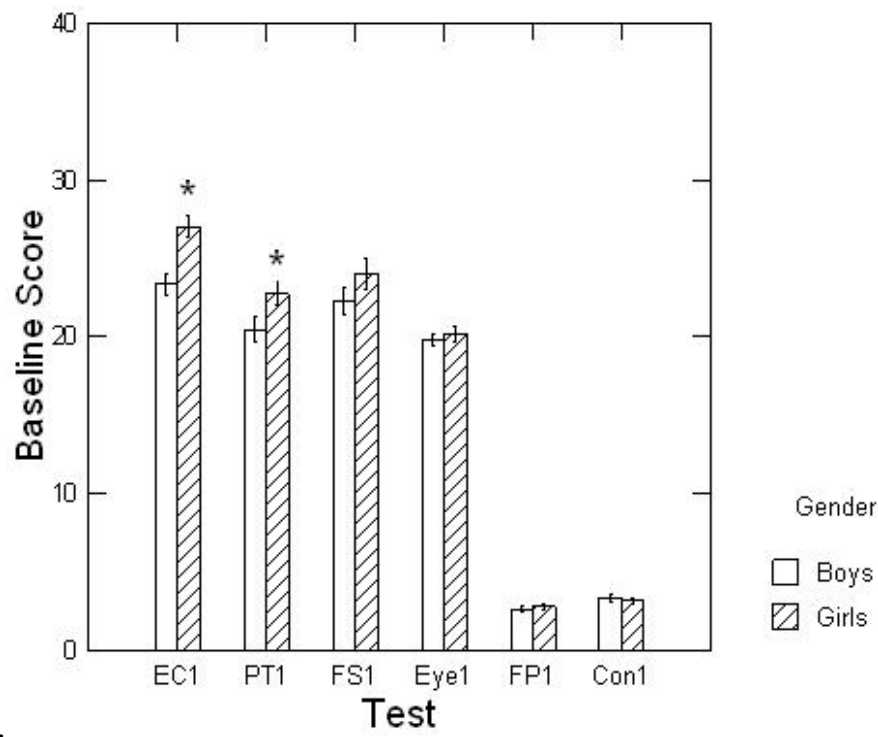

Fig. 1a.
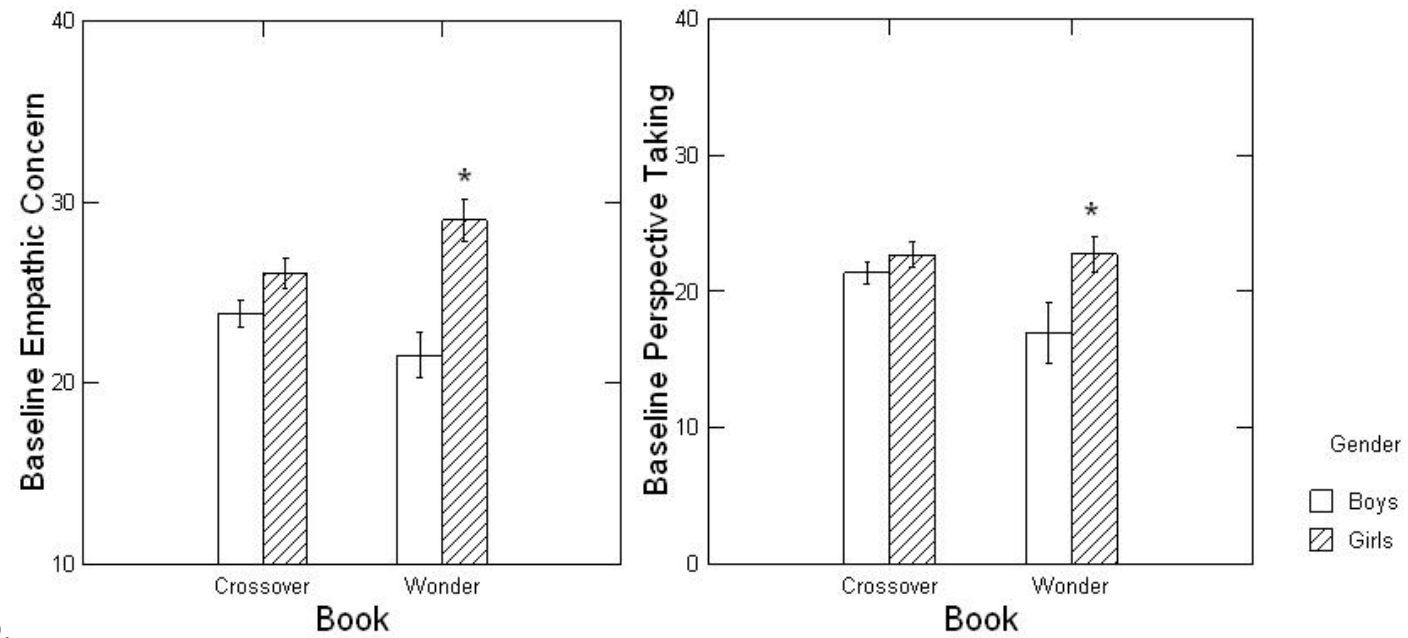

Fig. 1b. Book 
Fig. 1c.

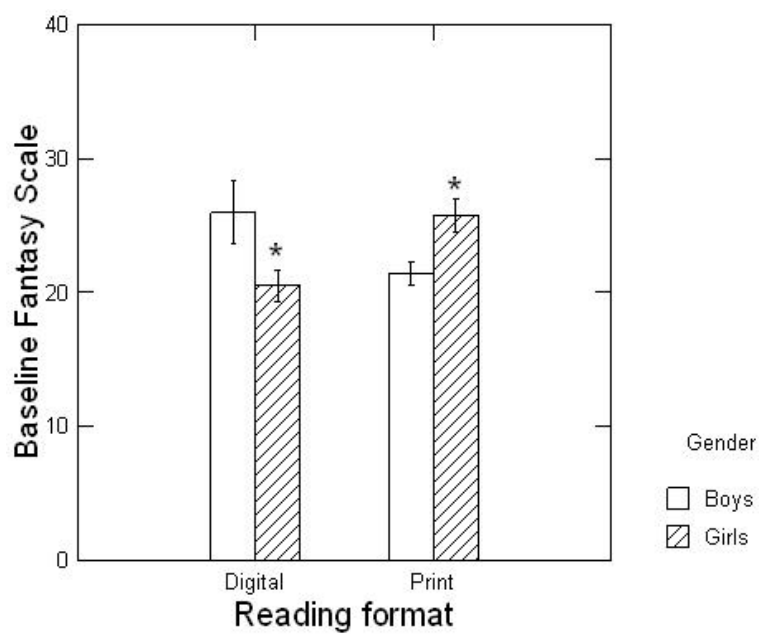

1a. Girls had significantly higher baseline scores than boys in Empathic Concern and Perspective Taking, but not in the other four measures. 1b. Gender differences were larger in the group that choose Wonder $(\mathrm{N}=21)$ than in the group that choose The Crossover $(\mathrm{N}=57)$. Pre-existing personality differences may have affected the children's choice of book, with boys who were lower in empathy preferring Wonder. Fig. 1c. Gender differences in Fantasy Scale depended on the anticipated book format. Among students who anticipated digital $(\mathrm{N}=20)$, boys had higher scores than girls; the difference was the opposite in those who anticipated print $(\mathrm{N}=58) .{ }^{*}$ Gender difference significant at $p<0.05$. EC1 = Empathic Concern, PT1= Perspective Taking, FS1= Fantasy Scale, Eye1 = Reading the Mind in the Eyes, FP1 = Score on faux pas questions, Con1 = Score on control questions. Maximum score for EC, PT and FS was 35; maximum score for EyesC was 28; maximum score for FP and Con was 5. 


\section{FIGURE 2}

Scores on the Interpersonal Reactivity Index Before and After the Reading Units

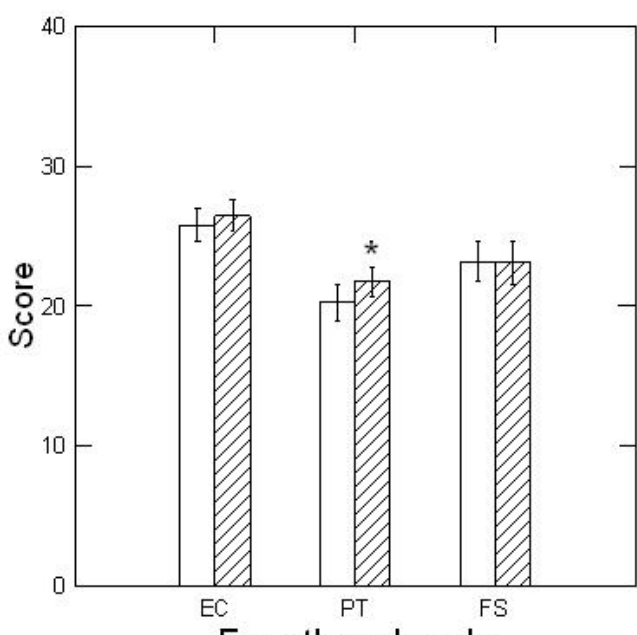

$$
\begin{aligned}
& \text { TME } \\
& \square \text { Before Wonder } \\
& \square \text { After Wonder }
\end{aligned}
$$

Fig. 2a.

Empathy subscale

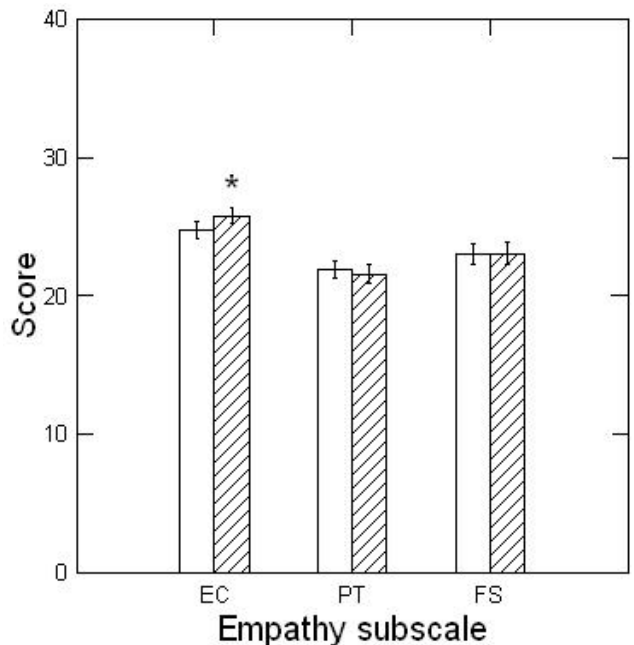

$$
\begin{aligned}
& \text { TME } \\
& \square \text { Before Crossover } \\
& \square \text { After Crossover }
\end{aligned}
$$

Fig. 2b.

Empathy subscale 
Fig. 2c.

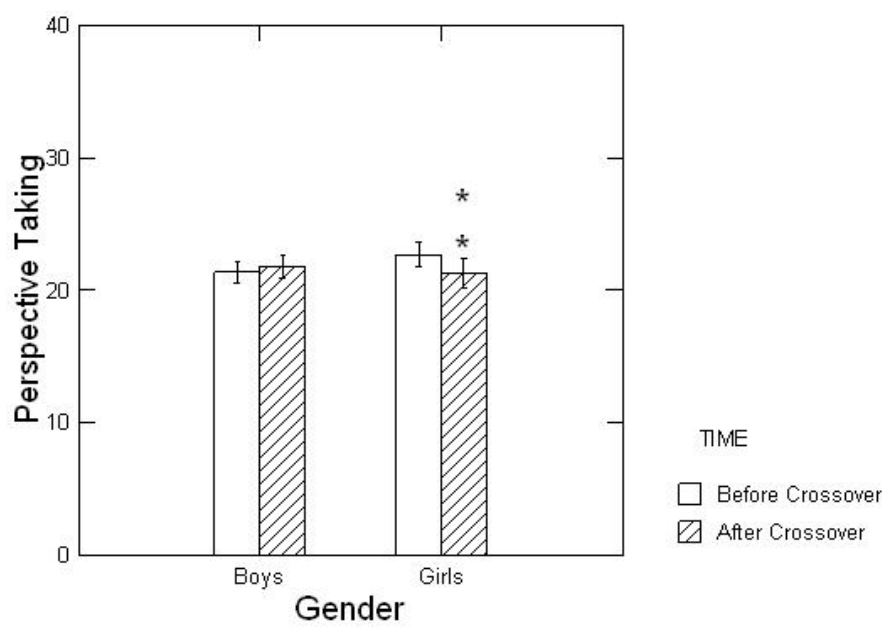

Fig. 2a. For students who read Wonder, only Perspective Taking increased after the unit. Fig. $2 b$. For students reading The Crossover, only Empathic Concern increased after the unit, Fig. 2c. For boys reading The Crossover, Perspective Taking did not change after the unit; for girls, scores trended downward slightly. ${ }^{*}$ Significantly different after reading unit, $p<0.05$. * ${ }^{*}$ Trend towards significance, $p=0.062 . \mathrm{EC}=$ Empathic Concern, $\mathrm{PT}=$ Perspective Taking, $\mathrm{FS}=$ Fantasy Scale. 


\section{FIGURE 3}

Scores on the Theory of Mind Tests Before and After the Reading Unit

Fig. 3a.

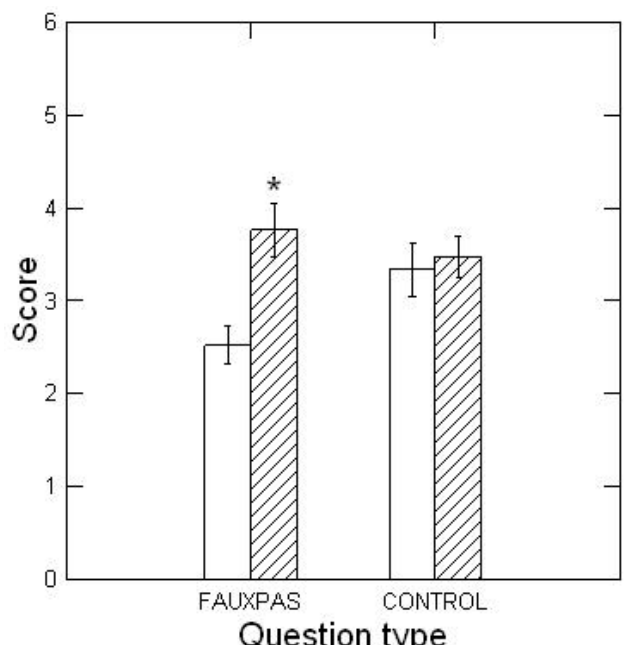

$$
\begin{aligned}
& \text { TIME } \\
& \square \text { Before Wonder } \\
& \square \text { After Wonder }
\end{aligned}
$$

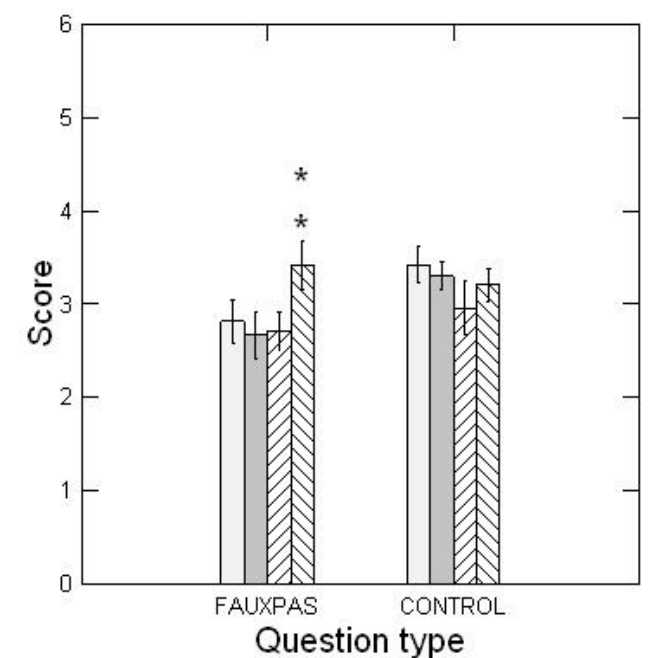

$\square$ Boys, Before Crossover

Boys, After Crossover

$\square$ Girls, Before Crossover

$₫$ Girls, After Crossover

Fig, 3b.

Question type 


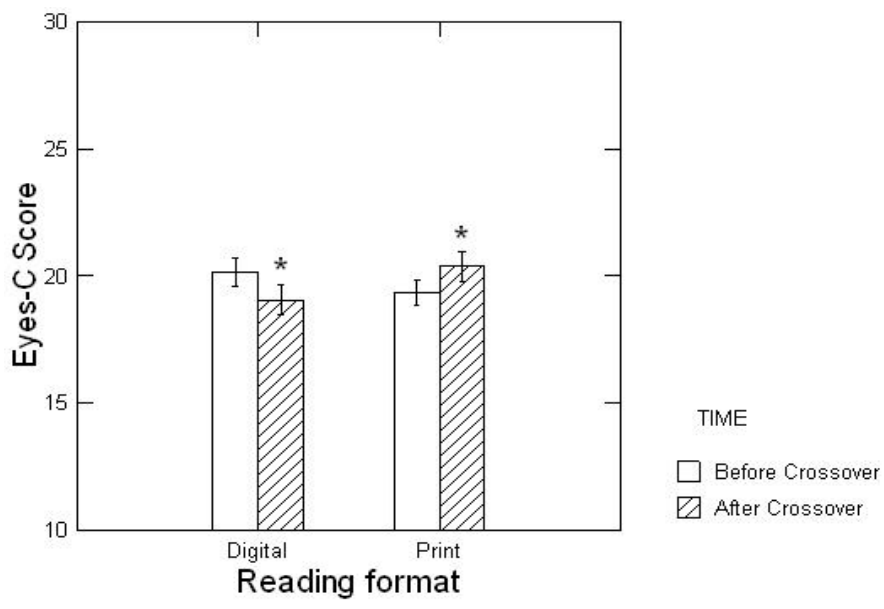

Fig, 3c.

Fig. 3a. Scores on faux pas recognition questions, but not control questions, increased in students who read Wonder, suggesting that this academic unit specifically increased the ability to detect social gaffes caused by missing or incorrect information. Fig. 3b. For students reading The Crossover, the increase in faux pas detection bordered on significance and was restricted to girls. There were no differences among the control scores. Fig. 3c. Effects on the Eyes-C test score for The Crossover readers depended on reading format. Those reading print form improved in their ability to interpret emotions from pictures of eyes, while those using iPads went down on that measure. There were no significant changes in the control scores. * Significantly different effect after reading unit, $p<0.05$. * Trend towards significance, $p=0.059$.

MARTHA S. GUARISCO is a National Board Certified English Language Arts teacher, writer, and library enthusiast. Prior to joining the faculty at Episcopal of Baton Rouge 14 years ago, she taught in Ascension Parish, where she was Teacher of the Year. She earned both her BA in English literature and her M.Ed. in English education from Louisiana State University

CELINE BROOKS is a biology technician at West Virginia University. She earned her BS in Psychology and Chemistry from Mary Baldwin College. Her interest in the social benefits of reading fiction emerged during her junior year of college when she collaborated with Dr. Louise Freeman on a course project. She is an avid reader of young adult literature and hopes that the growing support for fiction will encourage its use in the classroom. 
LOUISE M. FREEMAN is a Professor of Psychology at Mary Baldwin University, where she has taught for 17 years. A behavioral neuroscientist by training, she expanded her research into the psychological effects of young adult literature after enjoying series like Harry Potter, The Hunger Games, and Divergent with her children. She has also recently begun providing applied behavior analysis services to children with autism. She has presented work on psychology and young adult fiction at multiple academic conferences and blogs regularly at www.hogwartsprofessor.com. 